\title{
La Ética Pública en México, Chile y Colombia. Un estudio de derecho comparado
} Public Ethics in Mexico, Chile and Colombia. A study of comparative law

\section{Dr. Rodolfo Elizalde Castañeda ${ }^{1}$}

rodolfoelizaldecas@yahoo.com.mx

Universidad Autónoma del Estado de
Mayra Sánchez Garduño

smayra264@gmail.com

Universidad Autónoma del Estado de México

México

\section{RESUMEN}

El objetivo de este trabajo es analizar algunos de los documentos normativo-institucionales que regulan los valores éticos que identifican la conducta de los servidores públicos de México, Chile y Colombia, con el fin de conocer sus similitudes y diferencias, para lo cual utilizaremos el método comparado; desde luego, sin profundizar en éste con todo su rigor, dadas las características propias de este ensayo. Los tres países heredaron los valores de los padres del Contrato Social, sin embargo, estos han sido histórica, política, social y culturalmente cuestionados por muchos motivos, en especial, por la enorme infuencia de la doctrina neoliberal.

Palabras claves: ética pública; gobierno federal; gobierno central; administración pública; Estado constitucional democrático de derecho.

\section{ABSTRACT}

The objective of this work is to analyze some of the normative-institutional documents that regulate the ethical values that identify the conduct of public servants in Mexico, Chile and Colombia, in order to know their similarities and differences, for which we will use the method compared; certainly, without going into it with all its rigor, given the characteristics of this essay. The three countries inherited the values of the parents of the social contract; however, these have been historically, politically, socially and culturally questioned for many reasons, especially, due to the enormous influence of the neoliberal doctrine.

Keywords: public ethics; federal government; central government; Public administration; Democratic constitutional state of law.

1 Profesor-Investigador de Tiempo Completo del Centro de Investigaciones en Ciencias Jurídicas, Justicia Penal y Seguridad Pública (CICJJPySP), de la Facultad de Derecho de la Universidad Autónoma del Estado de México. Integrante del Sistema Nacional de Investigadores (SNI), Nivel 1.

2 Alumna del noveno semestre de la Facultad de Derecho de la Universidad Autónoma del Estado de México. 


\section{Introducción}

El objetivo de este ejercicio académico es analizar algunos de los documentos normativoinstitucionales que regulan los valores de la ética pública de los servidores públicos en México, Chile y Colombia, con el fin, básicamente, de identificar sus similitudes y diferencias. Consideramos trascendente y relevante histórica, social, jurídica y culturalmente realizar un estudio comparado sobre los valores que sustentan la ética pública de los servidores públicos de cada uno de esos países a partir de sus documentos institucionales, sobre todo, en una época tan marcada por el antivalor de la corrupción, tema este que, ninguno de los tres países se salvan; sin embargo, cabe aclarar que dadas las características de este ensayo, sería imposible profundizar con todo rigor en esa comparación. Actualmente, México, Chile y Colombia, están organizados constitucionalmente, el primero, bajo un régimen federal como se observa en la Constitución Política de los Estados Unidos Mexicanos (CPEUM, 1917, artículo 40); Chile y Colombia bajo un régimen central, como se desprende de la Constitución Política de la República de Chile (CPRCH, 1980, artículo 3º y la Constitución Política de la República de Colombia (CPRC, 1991, artículo 1º); pero, los tres tienen un mismo origen basado en el Estado liberal, que dio sustento al Estado Constitucional democrático de derecho, desde luego, con sus propias características y evolución histórica. Aunque, cabe señalar que, en palabras de Alan de Benoist (2013, p. 1), el liberalismo jamás se ha presentado "como una doctrina unificada". Y, agrega que, inclusive, "Los autores que se han reclamado de esta corriente han dado con mucha frecuencia interpretaciones divergentes, si no contradictorias de la misma". (2013, p. 1); en ese mismo sentido, también puede leerse el artículo de Rafael Domingo Sánchez (2012), titulado: "Una mirada critica del liberalismo", quien refiere la teoría desarrollada por uno de los ideólogos mas destacados de la teoría liberal, Friedrich Hayek.

Esto, consideramos, es causa suficiente para realizar el análisis comparativo que aquí se propone. No obstante, también cabe aclarar, que ese origen común, de ninguna manera significa que el marco jurídico-institucional que da sustento a sus valores éticos, sea el mismo para los tres países y, menos aun, que dicho marco sea una garantía del cumplimiento de sus valores. Por ese motivo revisaremos las constituciones y algunos de los códigos éticos de los países en estudio, pues a partir de su constitucionalización y legalización aquellos servidores públicos que no observen los valores éticos pueden ser sancionados, pues como toda norma jurídica constituyen un mandato que incluye la posibilidad, no solamente, de restringir la conducta de los servidores públicos, o sea, de quienes están al frente del propio Estado, y esto, hay que decirlo, abarca desde los titulares de los poderes ejecutivo, 
legislativo, judicial, pasando, ahora, por los órganos constitucionales autonomos, hasta el barrendero. Esto es, "La norma jurídica tiene como característica fundamental la coercitividad; si la voluntad dominada por la norma ---a la que se refiere la hipótesis de conducta--- no se comporta en los términos del mandato, podrá ser sancionada...”. (Sánchez, 2011, p. 132) En otras palabras, si algun servidor público atenta en contra de esas normas, la consecuencia sería aplicar las sanciones penales y administrativas que correspondan.

El método comparado, con las reservas que anterioremente señalamos, nos permite analizar algunos cambios constitucionales y legales de los países en estudio, para ampliar nuestros horizontes históricos, sociales, jurídicos y culturales, en este caso concreto, sobre los valores éticos que pretenden regular la conducta de los servidores públicos, para darnos cuenta, finalmente, de las similitudes y diferencias que hay entre ellos, especificamente, en ese tema.

Las preguntas que guiarán este ejercicio académico son: ¿Cuál es el marco normativoinstitucional que pretende regular la conducta ética de los servidores públicos de México, Chile y Colombia? ¿Cuáles son los valores que identifican actualmente a la ética pública de los funcionarios públicos de México, Chile y Colombia? ¿Cuáles son las similitudes y diferencias de los valores éticos de los funcionarios públicos de México, Chile y Colombia?

\section{Algunas ideas conceptuales}

\section{a. Ética Pública.}

Zoé Robledo refiere que, "La ética esta en todas partes" (Diego, 2013b, p. 5); pero, la ética pública es inherente y exclusiva de los servidores públicos; además, es un tema que está en el centro de la ciencias, entre otras, el derecho, pues la encontramos sustentada en el mismo derecho constitucional y el derecho administrativo, así como en la ciencia política, o sea, en el derecho público, ya que ellas abordan y regulan, entre otros aspectos, la función pública de los funcionarios públicos, basadas en un marco de valores éticos en relación con su desempeño para ofrecer un servicio de calidad y garantizar la protección de las libertades y derechos fundamentales de los ciudadanos. (Elizalde y Aguilera, 2021) Por su parte, Oscar Diego, coincide con estas ideas, cuando nos dice que, "Históricamente, la ética ha estado vinculada a los asuntos de gobierno tanto en la formación de los gobernantes como durante la práctica política al conllevar acciones acompañadas de valores que benefician a los gobernados.” (2013b, p. 85). 
En México la ética pública no es nada más que "la ética aplicada y puesta en práctica en el ámbito público. La ética aplicada en los servidores públicos implica plena conciencia de su conducta, la cual se traduce en actos concretos orientados hacia el interés de la ciudadanía" (Diego, 2013a, p. 100). En otras palabras, los gobernantes y funcionarios deben guiarse por un conjunto de valores y virtudes en el cumplimiento de su deber para lograr el "bien común" de los ciudadanos. Por tal motivo, se afirma que la ética pública no solo son valores, sino que también es un modo de vida que permite tomar decisiones siempre en beneficio propio y de la comunidad. Por otro lado, los servidores públicos pueden utilizar a la ética pública como herramienta para el correcto desempeño de sus actos dentro del trabajo; de este modo se entiende que "la ética es una reflexión racional sobre la dimensión moral de la persona y puede caracterizarse como una reflexión, indispensable para el buen gobierno" (Vanegas, Moreno y Echeverri, 2020, p. 305)

Por su parte, Eber Betanzos refiere que, "las personas que integran y conforman dicha armazón institucional, son servidores públicos, quienes deben tener un actuar ejemplar, digno, respetable y honesto, en el que los valores y la moral constituyen los elementos primordiales de los ejes que guían los programas y políticas gubernamentales”. (2017, p. 19)

Continúa sosteniendo Oscar Diego en su libro, La ética y la corrupción en la política y la administración pública, que:

El descuido de la ética en la formación de gobernantes ha generado por un lado que aquellos que ocupan cargos públicos, al carecer de principios éticos, desvíen los fines originales de la política y de la administración pública al encontrarse demasiado obsesionados por sus intereses personales y partidistas. A su vez, el olvido de la ética en los gobernados ha generado su corrupción moral (2005, p. 41).

\section{b. Gobierno federal}

El federalismo latinoamericano tuvo una fuerte raigambre tomada de los Estados Unidos de Norteamérica. (Hamilton, Madison y Jay, 1974; Chaires, 2016, p. 20) Por su parte, este último autor, en su artículo "El fracaso del federalismo en Latinoamérica. Un estudio comparado con la cultura federal de los Estados Unidos de Norteamérica", cita la definición de Proudhon:

Federación, proviene del latín foedus, genitivo de foederis, que significa pacto, contrato, tratado, convención, alianza, etc., es un convenio por el cual uno o varios jefes de familia, uno o varios municipios, uno o varios grupos de municipios o Estados se obligan recíproca e igualmente 
los unos para con los otros, con el fin de cumplir uno o varios fines particulares que, desde entonces, pesan sobre los delegados de la federación de una manera especial y exclusiva. (citado por Chaires, 2017, p. 7)

El propio Chaires, agrega:

El federalismo en los países de Latinoamérica no ha funcionado. La autonomía de las provincias ha sido hábilmente utilizada por la élite gobernante local como subterfugio políticojurídico para encubrir la corrupción e impunidad. El federalismo en Latinoamérica, en lugar de servir para defender las diferentes culturas y tradiciones de las regiones y establecer límites al poder, ha impedido forjar los debidos pesos y contrapesos (2017, p. 0).

Esto que afirma Chaires en la cita anterior, lo podemos ver reflejado también en el México del siglo XXI, relacionado con la acusación que le hace la Ficalia General de la República, al Gobernador de Tamaulipas Francisco Javier Cabeza de Vaca, entre otras cosas, por defraudación fiscal (Ferri, 2021 y Vela, 2021).

\section{c. Gobierno central}

La palabra centralismo, etimológicamente deriva del latín centra, "un solo lugar" y lismo, "persona". Asi pues, es un sistema que concentra el poder y las funciones político-administrativas en un órgano central: el Estado como autoridad suprema, el cual atiende todo lo relativo a la administración, incluyendo los derechos públicos y colectivos.

En este tema, tenemos en primera instancia, el caso mexicano que, como dice José Saucedo, "marca la pauta sobre la "historia de los constituyentes mexicanos para apreciar la forma en que sus decisiones, con reconocida carga ideológica, han impactado a favor o en contra de nuestro proceso revolucionario." (Saucedo, 2018, p. 57) Así es como encontramos los dos bandos en los orígenes de la historia mexicana: federalistas y centralistas, confrontándose desde el constituyente de 1824 y reflejándose en las subsecuentes constituciones federalistas y centralistas. (Saucedo, 2018, pp. 61 y ss.)

Así pues, el centralismo es un sistema que implica una subordinación total de los poderes locales al poder central, otorgándole así todo el poder de decisión, buscando una unidad y capacidad de respuesta ante las necesidades de manera más eficiente (Gamborino, 2015).

d. Administración pública. 
Omar Guerrero refiere que la administración pública, "es la acción de las autoridades sobre los intereses y negocios sociales, que tengan el carácter público, ejercida conforme a las reglas que se hayan establecido para manejarlos" (Guerrero, 2002, pp. 29-30); mientras que Jorge Fernández Ruiz nos dice que el derecho administrativo:

es el conjunto de normas y principios del derecho público que rigen la estructura, organización, y funcionamiento de las diversas áreas de la administración pública, de las relaciones de éstas entre sí, así como de sus relaciones con las demás instituciones del Estado y con los particulares (De los Santos, 2012, p. 16).

Mientras que, el derecho administrativo es una rama del derecho público que tiene mayor énfasis en la administración pública, por lo que también mantiene una influencia estrecha con la ética pública, pues vigila las actividades de los servidores públicos desde un enfoque más cercano, sobre todo, si lo comparamos con el derecho constitucional. Dentro de su organización, cuenta con códigos y reglamentos específicos de cada una de las funciones de los funcionarios públicos, pero también alude al deber de cumplir con la atención hacia los ciudadanos y garantizar sus derechos fundamentales. En síntesis, se puede decir que la esencia del derecho administrativo radica en la defensa de los derechos de los ciudadanos en sus relaciones con la administración, por lo que los servidores públicos deben considerar un marco ético para generar una relación de armonía con los administrados, para que no caigan en el camino de la corrupción; pues las normas de derecho administrativo confieren poderes a la administración que la sitúan en posición de supremacía sobre los particulares.

\section{e. Estado Constitucional Democrático de Derecho.}

El derecho siempre a buscado la regulación de la conducta del hombre a través de las leyes que han fungido como directrices de los actos del ser humano; es por eso que existe una relación estrecha con la ética pública, pues, como señalan Jaime Rodríguez-Arana Muñoz:

la Ética, el ethos propio del Estado de Derecho, la gran matriz cultural de la democracia, está en la base del Derecho. Por una obvia razón, porque si el Estado de Derecho es una expresión de la justicia, el Derecho, es, debe ser, la misma justicia (2017, p. 67).

Mientras que, Enrique Sánchez Bringas nos dice que esta idea tiene sus antecedentes en la cultura helénica representada por Platón (428-347 a.c.) y Aristóteles (384-322 a.c.), donde el derecho, 
la justicia y el bien de la comunidad están inmersas, o mejor dicho, están simbióticamente unidos. (Sánchez, 2011, p. 26).

Por su parte, Kant y Humboldt refieren que el Estado de Derecho consiste en la: sujeción de la actividad estatal a la Constitución y a las normas aprobadas conforme a los procedimientos que ella establezca, que garantizan el cumplimiento responsable y controlado de los órganos del poder; el ejercicio de la autoridad conforme a disposiciones reconocidas y no retroactivas en términos perjudiciales, y la observancia de los derechos individuales, sociales, culturales y políticos (Witker, 2016, p. 31).

Asimismo, Witker refiere que:

el Estado democrático y social de derecho es un Estado (sobre todo) democrático, en que la democracia es entendida en dos sentidos armónicamente interrelacionados: por un lado, democracia política como método de designación de los gobernantes y por el otro, participación activa de los gobernados; y democracia social como la realización del principio de igualdad en la sociedad (2016, p. 33).

El Estado Constitucional de derecho surge "bajo el axioma de Constituciones rígidas, jerárquicamente supra ordenadas a las leyes como normas de reconocimiento de su validez". (Witker, 2016, p. 36) Mientras que, Mauricio Lara reafirma esta idea cuando sostiene que: la Constitución se fortalece:

a través de la efectiva tutela de los derechos por medio de garantías constitucionales, y de una nueva percepción de los derechos fundamentales, en el sentido de considerar que todas las normas del texto supremo tienen fuerza normativa, lo cual implica el fortalecimiento de los valores de contenido social, que por muchos años se dijo eran cláusulas programáticas. (2008, p. 823)

De esa manera, se entiende al Estado constitucional democrático de derecho, como aquel en el que, tanto el pueblo, como los poderes de éste, se unen por voluntad propia para formular sus propias legislaciones y después someterse a ellas, considerando los valores que tienen como nación; basándose en una ley suprema, que es la constitución, que, además, debe garantizar los derechos humanos y/o fundamentales de cada uno de los gobernados.

\section{La ética pública en México, Chile y Colombia}


Estos tres países tienen también otra coincidencia, surgieron a la vida independiente como un Estado constitucional democrático de derecho basado en el liberalismo clásico que surge de las ideas de los padres del Contrato Social, Hobbes (2005), Locke (1959) y Rousseau (1975). Precisamente, basados en la doctrina contractualista se deriva la ley suprema de cada uno de los países en estudio, mismo documento que da sustento a los valores éticos y deberes de sus servidores públicos; sin embargo, cabe mencionar que, en ejercicio de su libre albedrio, queda a cargo de estos la forma y el como deberían implementarlos dentro de su actividad. Por ese motivo, en este apartado se analizarán los documentos constitucionales y legales que dan sustento a la ética pública en los referidos países, revisando, al mismo tiempo, la perspectiva de algunos autores, como es el caso de Alejandro Serrano, quien refiriéndose a la política y a la ética, nos dice: “ambas, al menos en su sentido filosófico y desde su propia identidad, tienden al mismo fin: el bien" (2012, p. 2). Inclusive, este mismo autor va más allá, cuando refiere que, la crisis de la primera debido a la ruptura de los principios conceptuales en que surgió durante la época Moderna con base en el Contrato Social, hace necesaria la construcción de lo que él mismo denomina un "Nuevo Contrato Social Planetario" (2012, p. 1).

\section{a. La ética pública en México.}

México tiene un gobierno federal, así lo establece desde que nace la CPEUM vigente de 1917: Es voluntad del pueblo mexicano constituirse en una República representativa, democrática, laica y federal, compuesta por Estados libres y soberanos en todo lo concerniente a su régimen interior, y por la Ciudad de México, unidos en una federación establecida según los principios de esta ley fundamental (CPEUM, 1917, artículo 40).

Esa misma Carta Suprema estipula:

El pueblo ejerce su soberanía por medio de los Poderes de la Unión, en los casos de la competencia de éstos, y por los de los Estados y la Ciudad de México, en lo que toca a sus regímenes interiores, en los términos respectivamente establecidos por la presente Constitución Federal y las particulares de cada Estado y de la Ciudad de México, las que en ningún caso podrán contravenir las estipulaciones del Pacto Federal (CPEUM, 1917, artículo 41).

En México, el título IV de su Ley Suprema, se refiere a las responsabilidades de los servidores públicos, particulares vinculados con faltas administrativas graves o hechos de corrupción y patrimonial del Estado; en el que se identifica a los servidores públicos, como: 
representantes de elección popular, a los miembros del Poder Judicial de la Federación, los funcionarios y empleados y, en general, a toda persona que desempeñe un empleo, cargo o comisión de cualquier naturaleza en el Congreso de la Unión o en la Administración Pública Federal, así como a los servidores públicos de los organismos a los que esta Constitución otorgue autonomía, quienes serán responsables por los actos u omisiones en que incurran en el desempeño de sus respectivas funciones (CPEUM, 1917, artículo 108).

El 5 de febrero de 2019, se publica en el Diario Oficial de la Federación (DOF), el Código de Ética de las Personas Servidoras Públicas del Gobierno Federal (CEPSPGF), en el que se refiere que se trata de un instrumento deontológico que contiene los parametros: "de valoración y actuación respecto al comportamiento al que aspira una persona servidora pública, en el ejercicio de su empleo, cargo o comisión, a fin de promover un gobierno transparente, íntegro y cercano a la ciudadanía." (CEPSPGF, 2019, Artículo 4, fracción II) Ahora, con la reforma constitucional publicada en el DOF, el 19 de febrero de 2021, cabe la posibilidad de imputar y juzgar al propio presidente de la República, entre otras cosas, por hechos de corrupción. (CPEUM, artículo 108, segundo párrafo) Algunos de los valores que se desprenden de este precepto son la honestidad, la responsabilidad y la legalidad, con lo que podemos decir que la ética constitucional está inmersa en el máximo documento constitucional de donde se desprenden los códigos de conducta que establecen las diferentes responsabilidades en que pueden incurrir los servidores públicos, así como las sanciones a los que se hacen acreedores.

Igualmente, en el precepto citado se alude a las responsabilidades de los servidores públicos por violaciones a la Constitución Federal, a las leyes federales así como por el manejo y aplicación indebidos de fondos y recursos federales del orden local, que comprende las entidades federativas, los municipios y las alcaldias de la Ciudad de México y, de los miembros de los organismos a los que las constituciones locales les otorgue autonomía. Asimismo, se hace hincapié en que las constituciones locales establecerán el carácter de servidores públicos para el efecto de las posibles responsabilidades por el manejo indebido de recursos públicos y la deuda pública. Mientras que, los artículos 108 al 112 de la misma Ley Fundamental establecen las sanciones para los servidores públicos que incurran en alguna falta de las que se enuncian, así como el procedimiento; entre las cuales se encuentran el juicio político, sanciones penales y administrativas.

b. La ética pública en Chile. 
En el caso de Chile, es cierto que ha vivido la disputa entre la izquierda jacobina centralista y las izquierdas comunistas, federalistas y autonomistas, [...] Pero naturalizó el gobierno central como eje del desarrollo en un régimen político democrático donde se combina presidencialismo con centralismo[...]. (Valenzuela y Ortiz, 2017, p. 2; CPRCH, 1980, artículo $3^{\circ}$ )

Cabe señalar que uno de los máximos valores del modelo derivado del contrato social de Locke, es resaltado por la CPRCH:

El Estado está al servicio de la persona humana y su finalidad es promover el bien común, para lo cual debe contribuir a crear las condiciones sociales que permitan a todos y a cada uno de los integrantes de la comunidad nacional su mayor realización espiritual y material posible, con pleno respeto a los derechos y garantías que esta Constitución establece (1980, artículo $1^{\circ}$, párrafo tercero).

Este principio se complementa con el principio de probidad, igualmente, contemplado en su código supremo: "El ejercicio de las funciones públicas obliga a sus titulares a dar estricto cumplimiento al principio de probidad en todas sus actuaciones" (CPRCH, 1980, artículo $8^{\circ}$, párrafo primero). Como se observa, en torno a ambos principios gira la ética pública de los servidores públicos en la República de Chile.

Por su parte, el escritor Alejandro Serrano, no obstante que supra ya referimos que sostiene que la ética y la política tienden al mismo fin, más adelante refiere que:

en la Modernidad...ambas categorías, la ética y la política, han sido excluyentes. La política moderna, arranca, precisamente, de la supresión de la ética como categoría política y, correlativamente, de su fundamentación sobre otros supuestos y no sobre los supuestos éticos que estuvieron en su origen y en su razón primera. El mundo moderno día a día se fue alejando cada vez más de los presupuestos morales en el quehacer político; cada día la política se transforma en un valor en sí mismo y no en algo subordinado y sustentado sobre los principios morales, y cada día sus errores y horrores involucran a la humanidad en un torbellino que pareciera a veces indetenible. La crisis de la política, al menos en su sentido clásico, es mundial, y, a mi modo de ver, uno de los factores más importantes de la crisis de la modernidad. Quizás es en la política donde más se ha visualizado la crisis de la modernidad. El mundo ha visto la crisis de las ideologías, de la política, de la ética y de los sistemas, consecuencia de lo que algunos llaman la crisis global del racionalismo. (2012, p. 4) 
De lo anterior, se desprende que en esa evolución de la modernidad, los valores son los que más se han visto afectados, y tiene razón Alejandro Serrano, pues cada día las personas se deshumanizan y van perdiendo conciencia de lo que realmente es importante para lograr el bien común, el bienestar, el desarrollo de la sociedad y la felicidad; o sea, lo contrario de lo que expone Locke (1959), en su modelo de contrato social, es decir, pierden el interés general y solo se atiende el interés individual. Frente a esta situación, Patricio Orellana en su artículo "Crisis de la ética pública en Chile", comenta que:

El neoliberalismo exalta otros principios sociales: el egoísmo y la desigualdad social extrema, el éxito como fin social supremo, la deshumanización de las decisiones y la postergación de cualquier política social centrada en la salud, el empleo, la educación y en general el mejoramiento de la calidad de vida (2013, p. 2).

En síntesis, el neoliberalismo resalta los antivalores. Pero, que hacer para evitar que la ética se siga degradando, precisamente, se hace cada vez más urgente implementar la ética pública en el quehacer de los servidores públicos para generar una armonía dentro del país basándose en valores y generando un ambiente de paz y equidad, en donde, tanto la ciudadanía como el gobierno se encarguen de tomar las decisiones que sean más favorables, de esa manera se promoverá una mayor participación y podrá lograrse una reestructuración de las profundas rupturas en el Estado, la sociedad y la economía y en la elaboración del diseño de un nuevo sistema, si se quieren preservar algunos de los valores fundamentales. Como una respuesta a esa situación, en el año 2016 la República de Chile inicia la implementación de códigos de ética en todas las instituciones públicas a nivel central, comenzando con ello, "el desarrollo del Sistema de Integridad Público Chileno" (Carrizo y Durán, 2018, p. 25). Se trataba de "mejorar las competencias éticas de los funcionarios; prevenir actos de corrupción y faltas a la probidad y ética; y fortalecer la confianza ciudadana en el Estado...)" (Carrizo y Durán, 2018, p. 2).

Cabe destacar también que, la CPRCH establece ciertos lineamientos sobre los que se debe llevar a cabo la administración pública donde se garantiza la carrera funcionaria y los principios en que deba fundarse:

Una ley orgánica constitucional determinará la organización básica de la Administración Pública, garantizará la carrera funcionaria y los principios de carácter técnico y profesional en 
que deba fundarse, y asegurará tanto la igualdad de oportunidades de ingreso a ella como la capacitación y el perfeccionamiento de sus integrantes.

Cualquier persona que sea lesionada en sus derechos por la administración del Estado, de sus organismos o de las municipalidades, podrá reclamar ante los tribunales que determine la ley, sin perjuicio de la responsabilidad que pudiere afectar al funcionario que hubiere causado el daño (CPRCH, 1980, artículo 38).

No obstante lo antes expuesto, no podemos soslayar el contexto histórico; por ese motivo, cabe resaltar dos aspectos, primero, que la CPRCH de 1980, a la que nos hemos venido refiriendo, surgió de un gobierno como el de Augusto Pinochet, que llegó al poder después del Golpe de Estado contra el presidente Salvador Allende (11 de septiembre de 1973) y que aquél gobernó con base en la violencia y la fuerza basada en una dictadura militar; segundo, por tanto, los valores éticos antes referidos, encierran una enorme contradicción, pues en la creación de dicha Constitución se excluyó la participación de gran parte del pueblo chileno; o sea, las normas institucionales derivadas de esa dictadura fueron, en palabras de Chistian Viera, producto de una imposición democrática, aparente y autoritaria, que impuso, además, las políticas económicas neoliberales (2011, p. 152).

Derivado de la anterior situación, previa reforma constitucional del 24 de diciembre de 2019, que incorporó las reglas para establecer un Proceso Constituyente, el pasado 15 y 16 de mayo de 2021, se llevó a cabo la elección para elegir una Convención Constituyente con el objetivo de redactar una nueva Constitución, o sea, un nuevo contrato social, compromiso derivado del Plebiscito Nacional celebrado el 25 de octubre de 2020. Por lo que, a mediados de 2022, se llevará a cabo un nuevo Plebiscito Nacional con el único objeto de rechazar o aceptar la nueva Constitución, destacando que este proceso se realiza sin la participación de los partidos políticos tradicionales, ni de los poderes constituidos, además, de que en el citado Plebiscito Nacional para admitir o rechazar la nueva Constitución, el voto será obligatorio (Proceso Constituyente, 2019).

Como se puede observar, la ética pública está basada en la obligación y el deber de obedecer principios y normas, así como en la moral, para llevar a cabo el buen funcionamiento del Estado y tienen una conciencia de que lograr un buen gobierno es trabajo de todos, es decir, se debe aplicar la ética pública en general y aunque el funcionario es el responsable de la administración, mucho tiene que intervenir el ciudadano, para poder lograrlo. Sin embargo, la historia en Chile se continúa escribiendo. 


\section{c. La ética pública en Colombia.}

La Constitución de la República de Colombia, conocida como "La Constitución de Cúcuta, inspirada en las ideas del Libertador en 1821, estableció un sistema de gobierno completamente centralista. Los departamentos se convirtieron en simples entidades administrativas, sometidas al gobierno central a través de un funcionario llamado intendente.” (Chaires, 2017, p. 21) Posteriormente, adoptaría un gobierno federal, entre 1854 a 1886. Actualmente, como ya lo referimos supra, se rige bajo el sistema centralista.

Por otra parte, la propia CPRC establece el compromiso de los funcionarios públicos para con el pueblo:

Ningún servidor público entrará a ejercer su cargo sin prestar juramento de cumplir y defender la Constitución y desempeñar los deberes que le incumben.

Antes de tomar posesión del cargo, al retirarse del mismo o cuando la autoridad competente se lo solicite deberá declarar, bajo juramento, el monto de sus bienes y rentas.

Dicha declaración sólo podrá ser utilizada para los fines y propósitos de la aplicación de las normas del servidor público (CPRC, 1991, artículo 122).

Los servidores públicos son responsables ante las autoridades por infringir la Constitución y las leyes, "por omisión o extralimitación en el ejercicio de sus funciones" (CPRC, 1991, artículo 60); mientras que, previamente señala como uno de los principales compromisos del Estado, "servir a la comunidad, promover la prosperidad general y garantizar la efectividad de los principios, derechos y deberes consagrados en la Constitución” (CPRC, 1991, artículo 2º). Además, el mismo documento constitucional refiere que se busca que la administración del Estado se desempeñe bajo un marco de ética pública, estableciendo los lineamientos por los cuales se deben regir los servidores públicos:

Son servidores públicos los miembros de las corporaciones públicas, los empleados y trabajadores del Estado y de sus entidades descentralizadas territorialmente y por servicios.

Los servidores públicos están al servicio del Estado y de la comunidad; ejercerán sus funciones en la forma prevista por la Constitución, la ley y el reglamento.

La ley determinará el régimen aplicable a los particulares que temporalmente desempeñen funciones públicas y regulará su ejercicio (CPRC, 1991, artículo 123). 
Por ello, refiere Carlos Franco que la ética en Colombia juega "un papel muy importante, pues a través de ella el hombre logra la adaptación de un sistema de valores y creencias a esquemas personales y sociales reales" (2018, p. 2). Así pues, los colombianos explican e interpretan su realidad, descubriendo que a través de ella pueden asegurar una sociedad de unidad y de cohesión, y para lograr esta utopía, les a costado mucho esfuerzo pues han tenido que madurar a lo largo de la historia. Continúa señalando el autor en cita que:

en la actualidad colombiana el sector público está muy mal parado, especialmente por las malas decisiones que se han presentado en donde se ha visto afectada directamente la economía colombiana. Ejemplos claros de lo anterior, es el caso de la Refinería de Cartagena, la corrupción en las Gobernaciones de la Guajira, Casanare, Cartagena, entre otras; la inversión que realizó el Ministerio de Hacienda con Telecom, y así otras más decisiones que no reflejan de ninguna manera la ética profesional y mucho menos las decisiones correctas y responsables de funcionarios públicos (2018, p. 3)

Pero, a pesar del mal gobierno que ha ido atravesando, Colombia no se rinde y buscan que sus servidores públicos, puedan representarlos y gobernarlos con base en la ética, para que esos valores humanos no se sigan perdiendo. Por lo que, han considerado la necesidad de implementar una normatividad y organizaciones que puedan fomentar la ética pública dentro del desempeño como servidor público.

Entonces, se puede observar que la ética en Colombia se basa en el marco de la Constitución, de la legalidad, la legitimidad y el compromiso, así como la honestidad y la justicia; quedando claro que la ley regula la responsabilidad de los servidores públicos y la manera de hacerla efectiva; y dentro de esas mismas leyes también entra el Código de Procedimiento Administrativo y de lo Contencioso Administrativo, con los cuales cuentan los colombianos para proteger y garantizar los derechos y libertades de las personas, la primacía de los intereses generales, la sujeción de las autoridades a la propia Constitución y demás preceptos del ordenamiento jurídico, el cumplimiento de los fines estatales, el funcionamiento eficiente y democrático de la administración, y la observancia de los deberes del Estado y de los particulares.

III. Los valores que identifican la ética pública en México, Chile y Colombia. Similitudes y diferencias 
A continuación, se presenta un cuadro comparativo donde se identifican las analogías y diferencias respecto a los valores de los servidores públicos de México, Chile y Colombia, tomando como base los Códigos de Ética que elegimos de cada uno de estos países. En el caso de México tomamos como referente el precitado Código de Ética de las Personas Servidoras Públicas del Gobierno Federal promulgado en 2019, (CEPSPGF, 2019); por la República de Chile, escogimos el Código de Ética del Ministerio de Relaciones Exteriores mediante Resolución Exenta №33, aprobada el 4 de enero de 2017. (CEMRE, 2017) y, respecto a Colombia se utilizó el Código de Ética del Ministerio de Interior y Justicia, creado en 2008, (CEMIJ, 2008). Cabe señalar que dentro de los códigos de ética de Chile y Colombia no se encuentran enumerados sus valores y principios como es el caso de México.

Tabla 1. Cuadro comparativo de los valores éticos semejantes de México, Chile y Colombia.

\begin{tabular}{|c|c|c|c|}
\hline $\begin{array}{c}\text { Valores } \\
\text { semejantes }\end{array}$ & México & Chile & Colombia \\
\hline Lealtad & $\begin{array}{l}\text { Buscará que las personas } \\
\text { servidoras públicas } \\
\text { correspondan a la } \\
\text { confianza que el Estado } \\
\text { les ha conferido, a fin de } \\
\text { satisfacer el interés } \\
\text { superior de las } \\
\text { necesidades colectivas y } \\
\text { generar certeza plena de } \\
\text { su conducta frente a } \\
\text { todas las personas, } \\
\text { garantizando la } \\
\text { integridad; los valores de } \\
\text { interés público y entorno } \\
\text { cultural y ecológico, así } \\
\text { como las reglas de } \\
\text { integridad de }\end{array}$ & $\begin{array}{l}\text { Servimos con lealtad a } \\
\text { los intereses de Chile } \\
\text { y a nuestra institución } \\
\text { en cada lugar del } \\
\text { mundo }\end{array}$ & $\begin{array}{lrr}\text { Ser fiel a } & \text { los } \\
\text { principios y } & \text { valores } \\
\text { que rigen } & \text { al } \\
\text { Ministerio } & & \text { del } \\
\text { Interior. } & & \end{array}$ \\
\hline
\end{tabular}




\begin{tabular}{|c|c|c|c|}
\hline & $\begin{array}{l}\text { cooperación y } \\
\text { desempeño permanente } \\
\text { con la integridad. (art. 9) }\end{array}$ & & \\
\hline $\begin{array}{l}\text { No } \\
\text { discriminación }\end{array}$ & $\begin{array}{l}\text { Trato igualitario a todos } \\
\text { los individuos es } \\
\text { evitando cualquier } \\
\text { acción u omisión que } \\
\text { menoscabe la dignidad } \\
\text { humana, derechos, } \\
\text { libertades o constituya } \\
\text { alguna forma de } \\
\text { discriminación. (art. 13) }\end{array}$ & 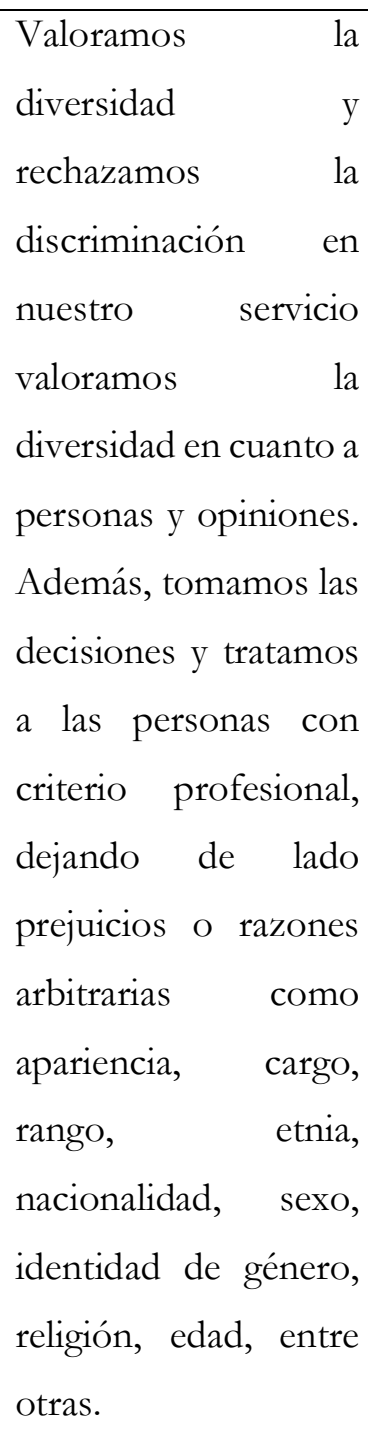 & $\begin{array}{l}\text { Satisfacción efectiva } \\
\text { de las necesidades de } \\
\text { la ciudadanía en el } \\
\text { campo de nuestras } \\
\text { competencias } \\
\text { brindamos atención } \\
\text { amable y oportuna sin } \\
\text { discriminación de } \\
\text { ninguna indole; } \\
\text { implementamos } \\
\text { mecanismos } \\
\text { permitan a la } \\
\text { comunidad conocer } \\
\text { los procesos y } \\
\text { resultados de la } \\
\text { gestión ministerial y } \\
\text { ejercer el control } \\
\text { social. }\end{array}$ \\
\hline $\begin{array}{l}\text { Honradez } \\
\text { Compromiso }\end{array}$ & $\begin{array}{l}\text { Fomentará la rectitud en } \\
\text { el ejercicio del empleo, } \\
\text { cargo o comisión } \\
\text { promoviendo un } \\
\text { gobierno abierto que }\end{array}$ & $\begin{array}{l}\text { Estamos } \\
\text { comprometidos y } \\
\text { comprometidas con } \\
\text { nuestra institución, } \\
\text { trabajamos con }\end{array}$ & $\begin{array}{l}\text { Actuar con } \\
\text { disposición, } \\
\text { convicción y entrega } \\
\text { en el cumplimiento de } \\
\text { nuestras obligaciones. }\end{array}$ \\
\hline
\end{tabular}




\begin{tabular}{|c|c|c|c|}
\hline & $\begin{array}{l}\text { promueva la máxima } \\
\text { publicidad y el escrutinio } \\
\text { público de sus funciones } \\
\text { ante la sociedad, } \\
\text { garantizando } \\
\text { transparencia y la } \\
\text { rendición de cuentas, así } \\
\text { como el valor de respeto. } \\
\text { (art. 8) }\end{array}$ & $\begin{array}{l}\text { vocación de servicio } \\
\text { para contribuir a la } \\
\text { defensa de los } \\
\text { intereses nacionales y } \\
\text { responder a las } \\
\text { necesidades de } \\
\text { nuestros usuarios. }\end{array}$ & \\
\hline $\begin{array}{l}\text { Comportamiento } \\
\text { digno o de } \\
\text { respeto }\end{array}$ & $\begin{array}{l}\text { Los servidores públicos } \\
\text { evitarán realizar } \\
\text { cualquier conducta que } \\
\text { constituya una violación } \\
\text { a los derechos humanos, } \\
\text { con el objeto de generar } \\
\text { ambientes laborales } \\
\text { seguros que privilegien } \\
\text { el respeto de las } \\
\text { personas. (art. 16) }\end{array}$ & $\begin{array}{l}\text { Fomentamos las } \\
\text { relaciones de trabajo } \\
\text { basadas en el buen } \\
\text { trato y la cordialidad, } \\
\text { reconocemos la } \\
\text { diversidad y los } \\
\text { distintos puntos de } \\
\text { vista como un reflejo } \\
\text { de nuestra orientación } \\
\text { hacia un mundo } \\
\text { globalizado. }\end{array}$ & $\begin{array}{l}\text { Reconocer, aceptar y } \\
\text { valorar las cualidades } \\
\text { del prójimo y sus } \\
\text { derechos. Implica } \\
\text { reconocer en sí y en } \\
\text { los demás la } \\
\text { condición humana y } \\
\text { sus obligaciones. }\end{array}$ \\
\hline
\end{tabular}

Fuente: Elaboración propia con información tomada de los Códigos de Ética de México, Chile y Colombia supra mencionados.

En esta tabla podemos identificar que son pocos los valores en los que coinciden los tres países, sin embargo, la lealtad, la honradez, y el respeto, así como el principio de no discriminación, son directrices generales por las cuales se guían mayormente; desde luego, salvo el caso de la república de Chile, que, como ya referimos, se trató de una Constitución disfrazada de democrata, lo que refleja una contradicción entre la teoría constitucional y legal con la realidad.

Tabla 2. Cuadro comparativo de los valores éticos diferentes en México, Chile y Colombia. 


\begin{tabular}{|c|c|c|c|}
\hline $\begin{array}{c}\text { Valores éticos } \\
\text { diferentes }\end{array}$ & México & Chile & Colombia \\
\hline Legalidad: & $\begin{array}{l}\text { Fomentará el } \\
\text { cumplimiento a las } \\
\text { normas jurídicas, con un } \\
\text { estricto sentido de } \\
\text { vocación de servicio a la } \\
\text { sociedad, garantizando el } \\
\text { profesionalismo, así } \\
\text { como los valores de } \\
\text { respeto a los derechos } \\
\text { humanos y liderazgo. } \\
\text { (art.7) }\end{array}$ & No lo menciona. & No lo menciona \\
\hline Igualdad & $\begin{array}{l}\text { Fomentarán la igualdad } \\
\text { entre mujeres y hombres, } \\
\text { y respetarán la identidad } \\
\text { y orientación sexual, con } \\
\text { el propósito de } \\
\text { contribuir a la } \\
\text { institucionalización de la } \\
\text { perspectiva de género en } \\
\text { el servicio público. (art. } \\
\text { 14) }\end{array}$ & No lo menciona & No lo menciona \\
\hline Eficiencia & $\begin{array}{l}\text { Buscará consolidar los } \\
\text { objetivos } \\
\text { gubernamentales a través } \\
\text { de una cultura de servicio } \\
\text { público austero, } \\
\text { orientada a resultados y }\end{array}$ & No lo menciona & No lo menciona \\
\hline
\end{tabular}




\begin{tabular}{|c|c|c|c|}
\hline & $\begin{array}{l}\text { basada la } \\
\text { optimización de } \\
\text { recursos, garantizando la } \\
\text { eficacia, la economía y la } \\
\text { disciplina, así como el } \\
\text { valor de cooperación. } \\
\text { (art. 11) }\end{array}$ & & \\
\hline Imparcialidad & $\begin{array}{l}\text { Buscará fomentar el } \\
\text { acceso neutral y sin } \\
\text { discriminación de todas } \\
\text { las personas, a las mismas } \\
\text { condiciones, } \\
\text { oportunidades } \\
\text { beneficios institucionales } \\
\text { y gubernamentales, } \\
\text { garantizando así la } \\
\text { equidad, la objetividad y } \\
\text { la competencia por } \\
\text { mérito; los valores de } \\
\text { equidad de género e } \\
\text { igualdad y no } \\
\text { discriminación y la regla } \\
\text { de integridad de } \\
\text { comportamiento digno. } \\
\text { (art. 10) }\end{array}$ & No lo menciona & No lo menciona \\
\hline Profesionalismo & No lo menciona & $\begin{array}{l}\text { Buscamos resultados } \\
\text { de excelencia, } \\
\text { realizando nuestro } \\
\text { trabajo con } \\
\text { responsabilidad y }\end{array}$ & No lo menciona \\
\hline
\end{tabular}




\begin{tabular}{|c|c|c|c|}
\hline & & $\begin{array}{l}\text { seriedad, generando } \\
\text { redes de colaboración } \\
\text { dentro y fuera de la } \\
\text { institución. }\end{array}$ & \\
\hline $\begin{array}{l}\text { No al acoso } \\
\text { sexual }\end{array}$ & No lo menciona & $\begin{array}{l}\text { En nuestra institución } \\
\text { rechazamos todo tipo } \\
\text { de conducta de acoso } \\
\text { sexual, se entiende } \\
\text { por tal "el que una } \\
\text { persona realice en } \\
\text { forma indebida, por } \\
\text { cualquier medio, } \\
\text { requerimientos de } \\
\text { carácter sexual, no } \\
\text { consentidos por quien } \\
\text { los recibe y que } \\
\text { amenacen } \\
\text { perjudiquen } \\
\text { situación laboral o sus } \\
\text { oportunidades en el } \\
\text { empleo". }\end{array}$ & No lo menciona \\
\hline $\begin{array}{l}\text { No al acoso } \\
\text { laboral }\end{array}$ & No lo menciona & $\begin{array}{l}\text { Rechazamos } \\
\text { cualquier tipo de } \\
\text { acoso laboral, } \\
\text { entendido como: } \\
\text { “toda conducta que } \\
\text { constituya agresión u } \\
\text { hostigamiento } \\
\text { reiterados, ejercida } \\
\text { por el empleador o }\end{array}$ & No lo menciona \\
\hline
\end{tabular}




\begin{tabular}{|c|c|c|c|}
\hline & & $\begin{array}{l}\text { por uno o más } \\
\text { trabajadores, en } \\
\text { contra de otro u otros } \\
\text { trabajadores, por } \\
\text { cualquier medio, y } \\
\text { que tenga como } \\
\text { resultado para el o los } \\
\text { afectados } \\
\text { menoscabo, maltrato } \\
\text { o humillación, o bien } \\
\text { que amenace o } \\
\text { perjudique } \\
\text { situación laboral o sus } \\
\text { oportunidades en el } \\
\text { empleo." }\end{array}$ & \\
\hline Transparencia & No lo menciona & $\begin{array}{l}\text { Facilitamos el acceso } \\
\text { a la información de } \\
\text { carácter público, } \\
\text { cumpliendo con los } \\
\text { plazos legales para } \\
\text { responder a las } \\
\text { solicitudes de la } \\
\text { ciudadanía. Además, } \\
\text { mantenemos } \\
\text { actualizados } \\
\text { habilitados los canales } \\
\text { de consulta } \\
\text { información. }\end{array}$ & $\begin{array}{l}\text { Demostrar } \\
\text { continuamente los } \\
\text { resultados de nuestra } \\
\text { gestión pública sin } \\
\text { omitir detalle alguno. }\end{array}$ \\
\hline Justicia & No lo menciona & No lo menciona & $\begin{array}{lll}\text { Reconocer } & & \text { los } \\
\text { derechos } & \text { que } & \text { le }\end{array}$ \\
\hline
\end{tabular}




\begin{tabular}{|c|c|c|c|}
\hline & & & $\begin{array}{l}\text { asisten a cada } \\
\text { persona, dando a cada } \\
\text { uno lo que es suyo. }\end{array}$ \\
\hline Responsabilidad & No lo menciona & No lo menciona & $\begin{array}{l}\text { Cumplir } \\
\text { integralmente y con } \\
\text { empeño nuestras } \\
\text { competencias } \\
\text { deberes y } \\
\text { servidores públicos. }\end{array}$ \\
\hline Solidaridad & No lo menciona & No lo menciona & $\begin{array}{ll}\text { Condición } & \text { del } \\
\text { servidor público con } \\
\text { la ciudadanía y los } \\
\text { compañeros de su } \\
\text { entidad para brindar } \\
\text { asistencia y justicia } \\
\text { social. }\end{array}$ \\
\hline Servicio & No lo menciona & No lo menciona & $\begin{array}{l}\text { Brindar la } \\
\text { información } \\
\text { atención oportuna de } \\
\text { forma amable y eficaz } \\
\text { a las personas que } \\
\text { necesitan de nuestra } \\
\text { ayuda y colaboración }\end{array}$ \\
\hline Honestidad & No lo menciona & No lo menciona & $\begin{array}{lr}\text { Desempeñar } & \text { nuestra } \\
\text { función } & \text { como } \\
\text { servidores públicos } \\
\text { utilizando recursos, } \\
\text { tiempo y espacio, con } \\
\text { el objeto para el cual }\end{array}$ \\
\hline
\end{tabular}




\begin{tabular}{|l|l|l|l|}
\hline & & & fueron constituidos. \\
\hline Tolerancia & No lo menciona & No lo menciona & Aceptar \\
recíprocamente las \\
diferencias existentes \\
entre las personas \\
para mantener una \\
convivencia armónica \\
en nuestra sociedad.
\end{tabular}

Fuente: Elaboración propia con información tomada de los Códigos de Ética de México, Chile y Colombia supra mencionados.

Como se desprende de la segunda tabla, cada uno de los países en estudio tiene sus propios valores que los hacen diferentes, pero lo importante es que los tres coinciden en fomentar la ética pública y su práctica desde sus Códigos Supremos para lograr una mejor administración pública dentro de sus respectivos países, por lo que, los tres son aparentemente congruentes al orientar a las y los servidores públicos hacia la adopción de principios, normas de conducta y valores que les permitan desempeñarse cada vez mejor para lograr los objetivos establecidos por el propio Estado constitucional democrático de derecho que ya hemos referido anteriormente. $\mathrm{O}$, como también lo sostiene Andrea Ramírez, refiriréndose a los servidores públicos:

la vocación se refiere a "actividades de especial excelencia intrínseca y a motivaciones e intenciones moralmente elevadas, desinteresadas", lo que significa que lo ideal es que los servidores públicos sean personas totalmente convencidas de querer desarrollar sus oficios no por la recompensa monetaria que este traiga, sino por la seguridad de querer servirle a la comunidad. Esto es fundamental para el aseguramiento del bienestar colectivo, ya que se trata de ansiar velar por el buen funcionamiento de las entidades del Estado (2016, p. 13).

A más de 200 años de haberse emitido la Declaración francesa de 1789 de los Derechos del Hombre y del Ciudadano (Jellinek, 2003), podemos decir que, en teoría, sigue vigente, en especial sobre el tema de la Constitución, cuando en su artículo 16 establece: "Toda sociedad en la cual la garantía de los derechos no está asegurada ni la separación de poderes establecida, no tiene Constitución.” Y decimos que en teoría, puesto que, de aquí se desprende el núcleo básico de toda 
Constitución, o sea, el conjunto de libertades y derechos humanos o fundamentales que el Estado debe garantizar a todas las persona y, esto involucra en nuestra opinión, desde luego, a los valores éticos, sobre todo, a partir de lo que comenta Gustavo Zagrebelsky (2008, p. 40), cuando nos dice que el derecho se vuelve un derecho más flexible, dúctil y maleable, en el cual la dimensión axiológica y deontológica tienen una mayor relevancia en la argumentación e interpretación jurídica. De este modo, también podemos decir que, en el Estado constitucional de derecho la ley pierde su preeminencia y queda supeditada a los principios y valores contenidos en la Constitución. Efectivamente, esos mismos valores los encontramos plasmados en las propias constituciones políticas de México, Chile y Colombia, así como en sus respectivos códigos de ética. Por lo que, en palabras de Hans Kelsen (1988), derivado de su famosa piramide normativa, estas normas secundarias están en correspondencia con su norma fundamental, lo que las impregna de los principios de constitucionalidad, supremacía y jerarquía jurídica, de donde derivan su fuerza normativa. Por lo que, si los tres países se rigen bajo un Estado constitucional democrático de derecho, lo correcto es que todos los funcionarios públicos están obligados a observar el marco constitucional y legal para lograr un buen gobierno y consecuentemente una buena administración pública, por lo que aquellos funcionarios públicos que falten a los valores éticos serán responsables penal y administrativamente de los actos en que incurran.

No obtante lo expuesto en el párrafo anterior, y aunque parezca contradictorio, no podemos dejar de soslayar el hecho de que, aun cuando los tres paises en estudio adoptaron un Estado constitucional democrático de derecho y crearon sus propios Códigos Éticos; en el caso de la nación chilena, a partir de la dictadura de Pinochet, que desconoció de facto la Constitución de 1825 y creó la Constitución de 1980; (Viera, 2011, p. 153) ésta aparentemente siguió, en teoría, los referidos postulados del citado artículo 16 de la Declaración francesa, pero, en la práxis diaria, con motivo del Golpe de Estado, las fuerzas armadas se encargaron de hacer todo lo contrario. Y, aun cuando, durante los 30 años posteriores a la dictadura (1973-1990), se llevaron a cabo infinidad de reformas constitucionales, incluyendo la creación del mencionado Código de Ética del Ministerio de Relaciones Exteriores, la idea presente entre muchos chilenos era que, la Constitución era producto de la dictadura militar. Por ese motivo, actualmente está en proceso la creación de una nueva Constitución, o sea, un nuevo contrato social. 


\section{A manera de conclusiones}

La esencia de valores, como la justicia, bien común, bienestar general, progreso, felicidad, paz, derivan del modelo del contrato social de Hobbes, Locke y Rousseau, en especial, del modelo propuesto por Locke, que, a su vez, dio origen al Estado constitucional, democrático de derecho. Por consiguiente, esos valores son los mismos que identifican constitucionalmente a países como México, Chile y Colombia. Pero, con la salvedad que hemos señalado sobre el Golpe Militar y la dictadura de Augusto Pinochet, que dio origen a la Constitución de 1980. No obstante, esos mismos valores, desde sus orígenes, han sido histórica, política, social y culturalmente cuestionados por muchos motivos, en especial, por la enorme infuencia de la doctrina neoliberal que ha predominado con sus antivalores desde hace varios años, lo cual, sin duda, ha provocado una enorme fractura jurídica y social en el desempeño y en la esencia del Estado constitucional, democrático de derecho y, evidentemente, esto ha ido de la mano del comportamiento de los servidores públicos.

Al margen de la organización federal o unitaria de los países en estudio, la relación entre la ética pública y el derecho constitucional que se ha dado entre ellos de manera natural, debido a sus orígenes y su evolución, salvo el caso de Chile que, después de la dictadura de Pinochet, esta en proceso de creación de un nuevo contrato social; podemos decir que, al revisar en este trabajo el marco normativo-institucional a partir de sus respectivas constituciones y algunos de sus códigos de ética, sus valores éticos quedaron plenamente identificados y, al mismo tiempo, también se establecieron sus similitudes y diferencias. Con lo cual, también podemos decir que se logró el objetivo establecido al principio de este trabajo. Precisamente, esas coincidencias hacen que comulguemos con Peter Häberle, cuando se refiere: "al indiscutible valor ético fundamental constitucionalizado". (1996, p. 162) Sin embargo, también debemos tener presente lo que refiere Oscar Diego:

El principal reto que afronta la ética en los cargos públicos no es el establecimiento de los valores sino su interiorización en las personas. Se sabe cuáles son los valores éticos deseables, pero lo que se ignora es cómo alcanzar ese “deber ser” en la práctica diaria. (2011, pp. 23-24)

En ese mismo sentido, igualmente podemos decir que se dio respuesta a cada una de las interrogantes que guiaron este trabajo. 


\section{REFERENCIAS BIBLIOGRÁFICAS}

Benoist, A. de (2013). Crítica de la ideología liberal. La Cuarta Teoría Política. https://4tpes.wordpress.com/2013/11/26/critica-de-la-ideologia-liberal/

Betanzos Torres, E. O. (2017). Notas en torno a la ética en el Servicio Público Mexicano. Revista de Administración Pública. (144), 15-33.

Carrizo Santiago, D. y Durán, F. (2018). Chile en la Implemantación Transversal de Código de Ética Pública: "La Ejecución de la Herramienta y el comienzo del Sistema de Integridad". [Archivo PDF]. https://www.serviciocivil.cl/wp-content/uploads/2018/05/Experiencia-c\%C3\%B3digosde- $\%$ C $3 \%$ A 9 tica-chile.pdf

Chaires Zaragoza, J. (2017). El fracaso del federalismo en Latinoamérica. Un estudio comparado con la cultura federal de los Estados Unidos de Norteamérica. Revista VLA IURIS. (23), 0-35. https://dialnet.unirioja.es/servlet/articulo?codigo $=6773366$

Código de Ética de las personas servidoras públicas del Gobierno Federal. (2019). Secretaria de la Función Pública. Diario Oficial de la Federación publicado el 5 de febrero del 2019. (México). https://dof.gob.mx/nota detalle.php?codigo $=5549577 \&$ fecha $=05 / 02 / 2019$

Código de Ética del Ministerio de Interior y Justicia. (2008). (Colombia). https://www.mininterior.gov.co/sites/default/files/codigo de etica3993.pdf

Código de Ética del Ministerio de Relaciones Exteriores. (2017). (Chile). https://minrel.gob.cl/minrel/ministerio/gestion-publica/codigo-de-etica-minrel

Constitución Política de la República de Chile. [Const.]. 1980. (Chile). https://www.oas.org/dil/esp/constitucion chile.pdf

Constitución Política de la República de Colombia. [Const.]. 1991. (Colombia). http://www.secretariasenado.gov.co/index.php/constitucion-politica

Constitución Política de los Estados Unidos Mexicanos. [Const.]. 1917. (México). http://www.diputados.gob.mx/LeyesBiblio/pdf/1 280521.pdf

De los Santos Morales, A. (2012). Derecho Administrativo I. Red Tercer Milenio.

Diego Bautista, O. (2011). Ética para Legislar. Poder Legislativo del Estado de México.

Diego Bautista. O. (2013a). De la ética a la ética pública. Revista LAPEM, (85), 83-104. 
Diego Bautista. O. (2013b). Ética para gobernar. Lecciones básicas para un gobierno justo. UAEM-Senado de la República, LXII legislatura.

Diego, O. (2006). La ética y la corrupción en la política y la administración pública. [Tesis maestría]. Universidad Internacional de Andalucía. https:/ / dialnet.unirioja.es/servlet/tesis?codigo $=20673$

Elizalde Castañeda, R.R. y Aguilera García, E. R. (2021). La ética pública en México y su relación con los derechos humanos y el derecho penal. Revista Ius Comitialis, 4(7), 192-206.

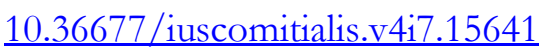

Ferri, P. (19 de mayo del 2021). Un Juez ordena la detención del gobernador de tamaulipas. El País. https://elpais.com/mexico/elecciones-mexicanas/2021-05-19/la-fiscalia-obtiene-orden-decaptura-contra-el-gobernador-de-tamaulipas.html.

Franco Cortazar, C. M. (2018). La ética en las organizaciones públicas en Colombia: Un panorama de lo que sucede en la actualidad y lo que se debe mejorar. Revista de la Universidad militar Nueva Granada, (1), 1-14.

Gamborino, P. M. (2015). Federalismo y centralismo, ¿una verdadera dicotomía?. Revista Hechos y Derechos, (27).

Guerrero, O. O. (2002). Nuevos aportes a la teoría de la administración pública en Luis Miguel Martínez Anzures (compilador), Antología sobre teoría de administración pública. (2 edición, pp. 25 40). Instituto Nacional de Administración Pública.

Häberle. P. (1996). La ética en el Estado constitucional. La relación de reciprocidad y tensión entre la moral y el derecho. Dereito, 5(2), 159-165.

Hamilton, Madison y Jay. (1974). El federalista. FCE.

Hobbes, T. (2005). Leviatán. O la materia, forma y poder de una repùblica eclesiástica y civil. (5a reimpresión, en Argentina). FCE.

Jellinek, G. (2003). La Declaración de los Derechos del Hombre y del Ciudadano. (Traducción y estudio preliminar de Adolfo Posada). UNAM.

Kelsen, H. (1988). Teoría General del Estado. (Trad. Eduardo García Máynez). UNAM. 
Lara Guadarrama, M. (2008). Democracia, Estado de Derecho y Estado Constitucional de Derecho. En Eduardo Ferrer Mac-Gregor y Arturo Zaldívar Lelo de Larrea (coordinadores). La ciencia del derecho procesal constitucional. Estudios en homenaje a Héctor Fix-Zamudio en sus cincuenta años como investigador del Derecho. (II, pp. 813-827). Universidad Nacional Autónoma de México. Instituto de Investigaciones Jurídicas.

Locke, J. (1959). Segundo Tratado de Gobierno. Agora.

Orellana Vargas, P. (2013). Crisis de la ética pública en Chile. Polis Revista Latinoamericana. (16), 1-26.

Proceso Constituyente. (2019). República de Chile. https://www.gob.cl/procesoconstituyente/

Ramírez Ramírez, A. M. (2016). Reflexiones sobre la ética en el actuar de los servidores públicos en Colombia desde 1991 hasta la actualidad. [Tesis]. Universidad Colegio Mayor de Nuestra Señora del Rosario.

Rodríguez Arana, J. (2017). La Ética pública Constitucional y la buena administración. Revista de Administración Pública. (3), 67-85.

Rousseau, J. J. (1975). El Contrato Social o principios de derecho político. Porrúa.

Sánchez Bringas, E. (2011). Derecho Constitucional. (12 edición). Porrúa.

Sánchez Domingo, R. (12 de enero 2012). Una mirada critica del liberalismo. Cisolog. https://cisolog.com/sociologia/una-mirada-critica-del-liberalismo/

Saucedo González, J. I. (2018). El federalismo y el centralismo como ideologías constructoras del Estado mexicano. En José Luis Soberanes Fernández y Eduardo Alejandro López Sánchez (coordinadores), 1916 rumbo a la Constitución de 1917 (pp. 57-84). Instituto de Investigaciones Jurídicas, Universidad Nacional Autónoma de México.

Serrano Caldera, A. (2012). Ética y Política. Polis, Revista Latinoamericana (10), 1-16.

Valenzuela, E. y Ortiz, E. (2017). La herencia centralista de la izquierda chilena y la irrupción de un progresismo regionalista autonomista. Izquierdas, (33), 174-202.

Vanegas Carvajal, E. A., Moreno López, V. y Echeverri Rendón, P. (2020). Ética de lo público: formar para la integridad humana y profesional en el contexto de la educación superior en Colombia. Revista CS, (31), 297-325. 10.18046/recs.i31.3251.

Vela, D. S. (2 de agosto de 2021). Gobernador de Tamaulipas pide a Corte anular orden de $\begin{array}{lllll}\text { aprehensión } & \text { en } & \text { contra. } & \text { financiero. }\end{array}$ 
https://www.elfinanciero.com.mx/estados/2021/08/02/gobernador-de-tamaulipas-pide-acorte-anular-orden-de-aprehension-en-su-contra/

Viera Álvarez, C. (2011). Análisis crítico de la génesis de la Constitución vigente. Revista de Derechos Fundamentales. (5), 151-171.

Witker Velazquez, J. (2016). Juicios orales y derechos humanos. Universidad Nacional Autónoma de México. Instituto de Investigaciones Jurídicas.

Zagrebelsky, G. (2008). El derecho dúctil. Ley, derechos, justicia. (8ª edición. Trad. de Marina Gascón). Trotta. 